\title{
Juvenile ossifying fibroma of the maxilla
}

\author{
Gagan Thakur, ${ }^{1}$ Preeti P Nair, ${ }^{2}$ Ravi Ahuja, ${ }^{3}$ Ruchi Ahuja ${ }^{4}$ \\ 1'Department of Oral and Maxillofacial Surgery, People's College of Dental Sciences and Research Center, Bhopal, India; \\ 2Department of Oral Medicine and Radiodiagnosis, People's College of Dental Sciences and Research Center, Bhopal, India; \\ ${ }^{3}$ Department of Pediatrics, Hind Medical College Barabanki, Lucknow, India; \\ ${ }^{4}$ Department of Pediatric Dentistry, Modern Dental College \& Research Center, Indore, India
}

Correspondence to Preeti P Nair, shajhoss@gmail.com

\section{Summary}

Juvenile ossifying fibroma (JOF), is a rare fibro-osseous neoplasm that arises within the craniofacial bones in individuals under 15 years of age. The term is used in the literature to describe two distinct histopathologic variants of ossifying fibroma of the craniofacial skeleton. It was described as a cellular and aggressive form of ossifying fibroma usually affecting children as 'the lesion proliferates, grows, invades and destroys tissue until the eyes are extruded and the cerebrospinal space is entered'. In the present case, because the lesion was well circumscribed and it was non-infiltrating into the adjacent bone and causing cosmetic and functional problems, surgical excision of the tumour mass was performed. A satisfactory facial appearance and an optimal restoration of function were achieved after the surgical procedure. After 3 months of follow-up, there was no recurrence.

\section{BACKGROUND}

Review of the literature shows that it is difficult to establish definitive diagnosis criteria for juvenile ossifying fibroma (JOF). This lesion is often difficult to diagnose from both clinical and histopathologic point of view. The main characteristics are: age $<15$ years, the location of the tumour, the radiologic pattern and tendency to recur. JOF is often seen in a very young child. Clinically, this lesion has in general a more aggressive growth rate than ossifying fibroma. Most cases of maxillary JOF are asymptomatic. JOF is often seen in very young children.

\section{CASE PRESENTATION}

An 8-year-old male child presented with a painless, progressive swelling of the left face for 6 months. Neither he nor his family had noteworthy history of JOF. Clinical examination revealed a large left facial mass localised to the left maxilla. Intraoral examination revealed gross expansion of the left maxillary alveolar process. There was minimal tenderness on palpation. The left maxillary deciduous molars were loose. There were no palpable cervical or submandibular lymph nodes.

\section{INVESTIGATIONS}

A postero-anterior Water's view radiograph showed a homogeneously hyperdense whole left maxilla and maxillary sinus.

Incisional biopsy was done and histopathological report suggested JOF.

\section{DIFFERENTIAL DIAGNOSIS}

- Fibrous dysplasia

- Cementifying fibroma

- Osteoblastoma.

\section{TREATMENT}

A maxillary left buccal vestibular incision was made and surgical excision of the tumour mass was performed under general anaesthesia. The tumour was removed wholly. The bony defect was filled with medical absorbable gelatin sponge - Abgel $\mathrm{IC}^{\mathrm{RC}}$ and sutured primarily figures $1-7$.

Microscopically, the lesion was non-encapsulated, showing infiltration of surrounding bone structures and reactive new bone formation at the periphery.

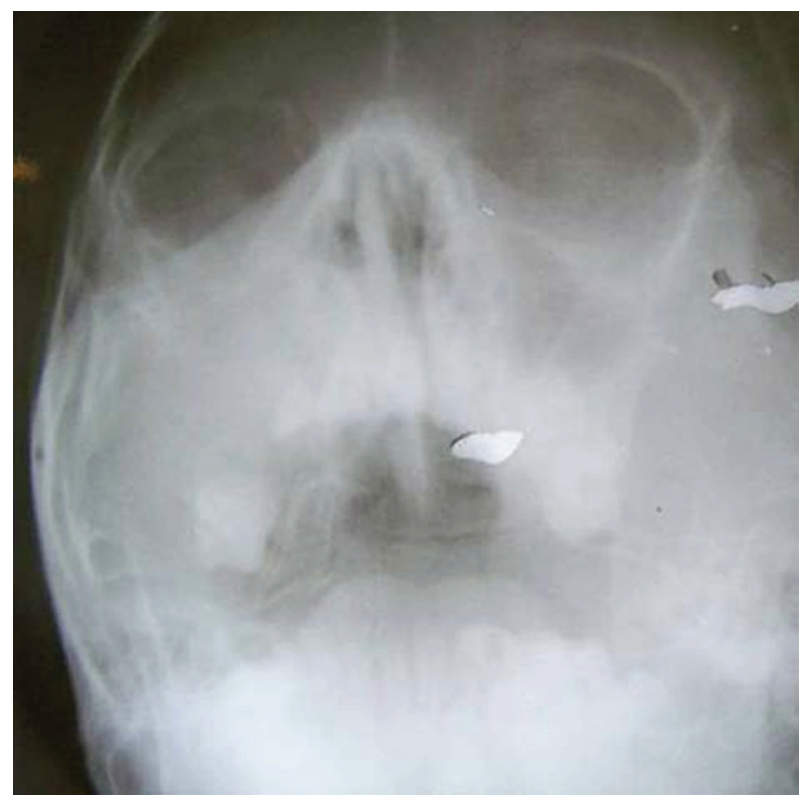

Figure 1 Para nasal sinus view. 


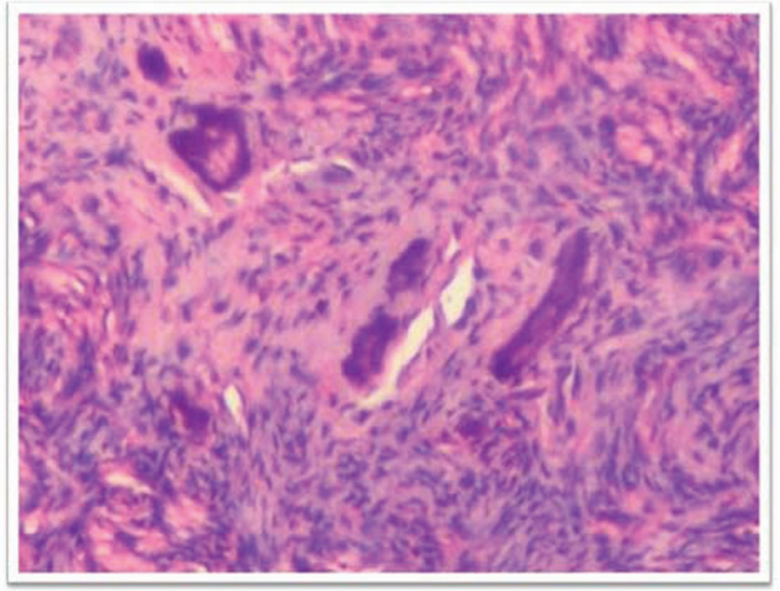

Figure 2 Histopathological slide picture.

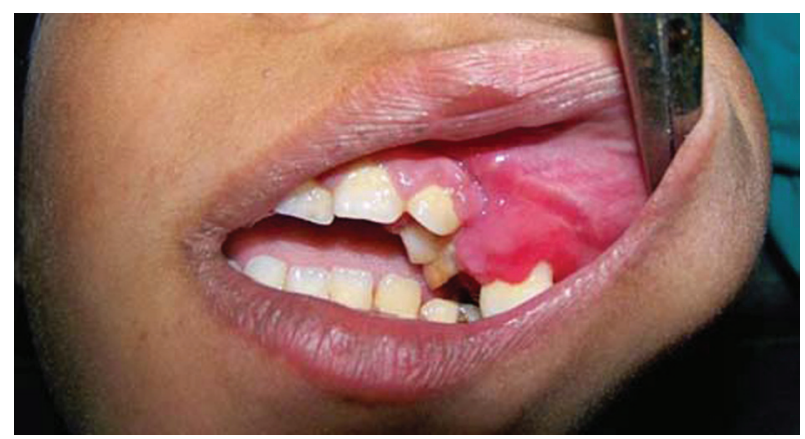

Figure 3 Intra oral presentation.

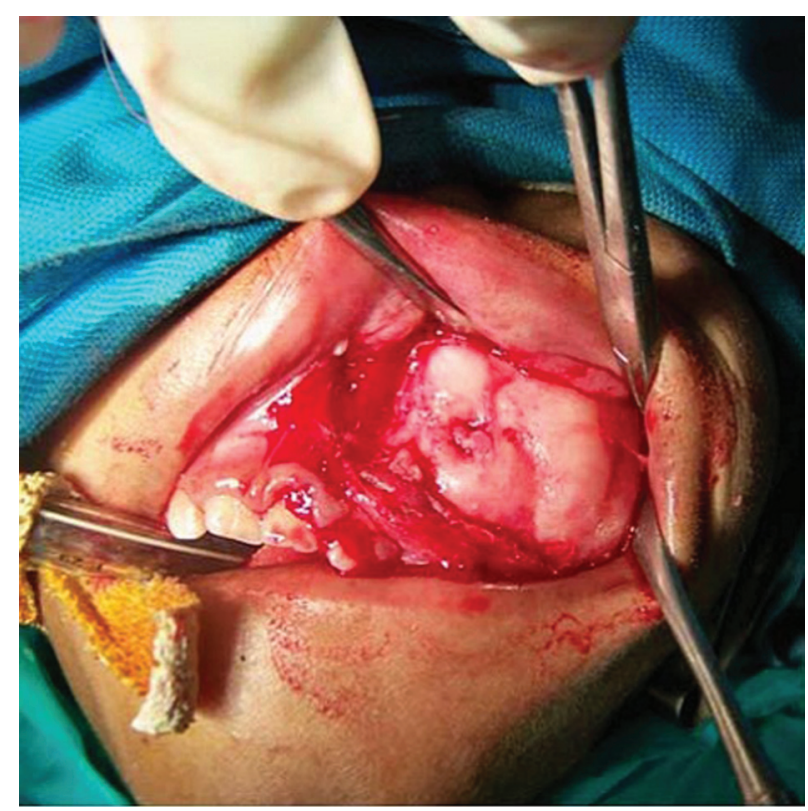

Figure 4 Tumour presentation.

\section{OUTCOME AND FOLLOW-UP}

A satisfactory facial appearance and an optimal restoration of function were achieved after the surgical procedure. After 3 months of follow-up, there was no recurrence.

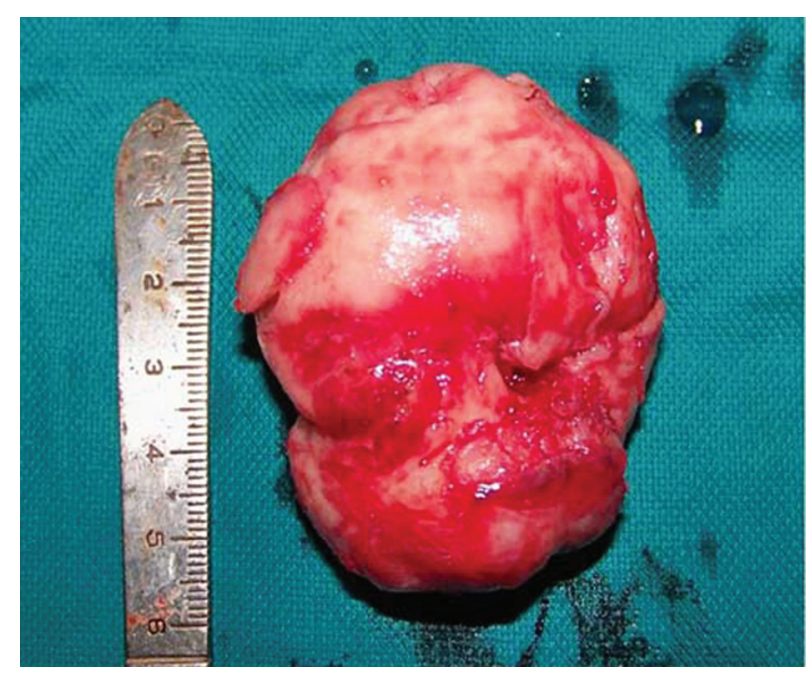

Figure 5 Excised tumour.

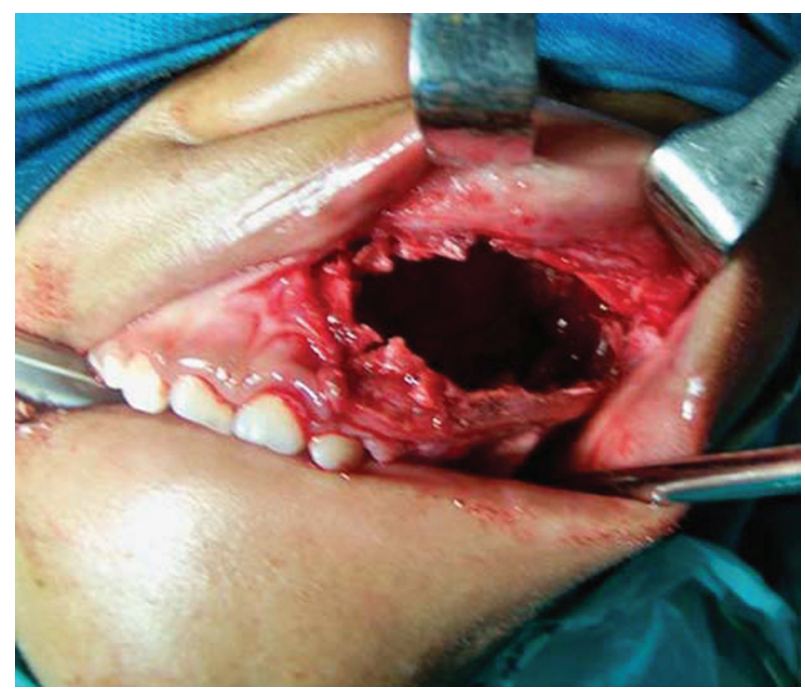

Figure 6 Residual defect.

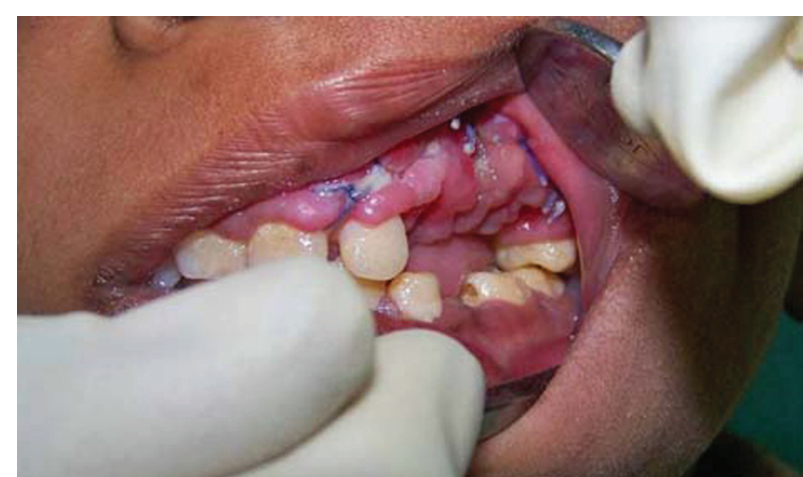

Figure 7 Intra oral wound 1 week postop.

\section{DISCUSSION}

As described in $\mathrm{WHO}^{1}$ histological typing of odontogenic tumours it is an actively growing lesion consisting of a cell rich fibrous stroma, containing bands of cellular osteoid without osteoblastic rimming, together with slender 
trabeculae of immature bone containing coarse lacunae with plump osteocytes and lined by a dense rim of enlarged osteoblasts. Pseudocysts were seen in the adjacent fibrocellular and myxoid stroma. Mitotic figures were observed in the stroma, especially in the cell-rich areas, but were never numerous.

Review of the literature shows that it is difficult to establish definitive diagnosis criteria for JOF. This lesion is often difficult to diagnose from both clinical and histopathologic point of view. The main characteristics are: age $<15$ years, the location of the tumour, the radiologic pattern and tendency to recur. JOF is often seen in a very young child. Clinically, this lesion has in general a more aggressive growth rate than ossifying fibroma. Most cases of maxillary JOF are asymptomatic. JOF is often seen in very young children. In reviews published by Hamner et $a l^{2}$ and Slootweg et $a l^{3}$ the mean age of onset was 11.5 and 11.8 years old, respectively.

The first clinical manifestation is a swelling of the maxilla, as seen in the present case. When the orbital bone and paranasal sinuses are involved, the patients may develop exophthalmos, bulbar displacement and nasal obstruction. The radiologic features are variable and depend on the tumour's location and the amount of calcified tissue produced by the tumour. The lesion shows varying degrees of radiolucency. Histologically, the lamellae are of variable shape, from trabecular to more osteoid, but at no time show 'Chinese character' shapes as are seen in fibrous dysplasia of bone. Haemorrhage is not prominent and when present is scattered rather than seen as foci, the latter being common in central giant cell granuloma. No obvious islands of epithelium or individual epithelial cells are present as seen in odontogenic fibroma. ${ }^{1}$ The stroma shows focal areas with stromal cysts and occasional mitoses. Cementicle-like particles are not seen. At the periphery of the lesion, cortical and reactive bone is sometimes seen.

The clinical management and prognosis of JOF is somewhat uncertain. There are few reports dealing with the issue of total care for these children, such as tumour resection, reconstruction and rehabilitation. ${ }^{4}$

The recurrence rate ranges from $30 \%$ observed by Johnson et at to $58 \%$ reported by Makek. ${ }^{6}$ Although many authors favour conservative surgery rather than radical en-bloc resection, immediate recurrence characterised by a high aggressive growth rate and the absence of a distinct separation between tumour and the adjacent bone requires extensive surgery, with wide demolition of the involved bone. $^{78}$

In the present case, because the lesion was well circumscribed and it was non-infiltrating into the adjacent bone and causing cosmetic and functional problems, surgical excision of the tumour mass was performed. A satisfactory facial appearance and an optimal restoration of function were achieved after the surgical procedure. After 3 months of follow-up, there was no recurrence.

\section{Learning points}

- Presentation of pathology at early childhood.

- Results in facial deformity.

- Can grow into adjacent vital structures.

- If diagnosed early and excised completely, results in complete recovery.

\section{Competing interests None}

Patient consent Obtained.

\section{REFERENCES}

1. Williams HK, Mangham C, Speight PM. Juvenile ossifying fibroma. An analysis of eight cases and a comparison with other fibro-osseous lesions. $J$ Oral Pathol Med 2000;29:13-18.

2. Hamner JE 3rd,Gamble JW, Gallegos GJ. Odontogenic fibroma. Report of two cases. Oral Surg Oral Med Oral Pathol 1966;21:113-19.

3. Slootweg PJ, Panders AK, Koopmans R, et al. Juvenile ossifying fibroma. An analysis of 33 cases with emphasis on histopathological aspects. J Oral Pathol Med 1994;23:385-8.

4. Sato M, Tanaka N, Sato T, et al. Oral and maxillofacial tumours in children: a review. Br J Oral Maxillofac Surg 1997;35:92-5.

5. Johnson LC, Yousefi M, Vinh TN, et al. Juvenile active ossifying fibroma. Its nature, dynamics and origin. Acta Otolaryngol Supp/ 1991;488:1-40.

6. Makek MS. So called "fibro-osseous lesions" of tumorous origin. Biology confronts terminology. J Craniomaxillofac Surg 1987;15:154-67.

7. Troulis MJ, Williams WB, Kaban LB. Staged protocol for resection, skeletal reconstruction, and oral rehabilitation of children with jaw tumors. J Oral Maxillofac Surg 2004;62:335-43.

8. Zama M, Gallo S, Santecchia L, et al. Juvenile active ossifying fibroma with massive involvement of the mandible. Plast Reconstr Surg 2004;113:970-4.

This pdf has been created automatically from the final edited text and images.

Copyright 2011 BMJ Publishing Group. All rights reserved. For permission to reuse any of this content visit

http://group.bmj.com/group/rights-licensing/permissions.

BMJ Case Report Fellows may re-use this article for personal use and teaching without any further permission.

Please cite this article as follows (you will need to access the article online to obtain the date of publication).

Thakur G, Nair PP, Ahuja R, Ahuja R. Juvenile ossifying fibroma of the maxilla. BMJ Case Reports 2011;10.1136/bcr.02.2011.3896, date of publication

Become a Fellow of BMJ Case Reports today and you can:

- Submit as many cases as you like

- Enjoy fast sympathetic peer review and rapid publication of accepted articles

- Access all the published articles

- Re-use any of the published material for personal use and teaching without further permission

For information on Institutional Fellowships contact consortiasales@bmjgroup.com

Visit casereports.bmj.com for more articles like this and to become a Fellow 